\title{
SINERGIA E CAPITAL SOCIAL NA CONSTRUÇÃO DE POLÍTICAS SOCIAIS: AFAVELA DA MANGUEIRA NO RIO DE JANEIRO
}

\author{
Maria Alice Nunes Costa
}

\begin{abstract}
RESUMO
Este trabalho analisa o programa de política social implantado na favela da Mangueira, no Rio de Janeiro, nas últimas duas décadas, entendendo-o como resultante de uma convergência de fatores que envolvem: 1) as transformações nas formas de gestão pública nas cidades brasileiras, que passaram mais recentemente a envolver parcerias dos governos local e estadual com a comunidade e as empresas; 2) a mudança na cultura empresarial, levando as empresas à atuação de caráter social, lado a lado com a política social dos governos e 3) a existência de laços comunitários em torno da Escola de Samba da Mangueira, que permitem entender essa entidade e seu entorno comunitário como dotados de capital social. Com base nos conceitos de capital social e governança estudamos o Programa Social da Mangueira como um caso de relativo sucesso de gestão descentralizada de política social, por meio de redes sociais estabelecidas entre a comunidade, o poder público e algumas empresas que vêm financiando inúmeros projetos culturais na favela da Mangueira.
\end{abstract}

PALAVRAS-CHAVE: governança; capital social; responsabilidade social empresarial; sinergia social.

\section{INTRODUÇÃO}

Este artigo tem como objetivo apresentar a análise realizada sobre o programa de política social implantado na favela da Mangueira, Rio de Janeiro, nas últimas duas décadas. Com base nos conceitos de "capital social" e "governança" estudamos o Programa Social da Mangueira como um caso de gestão descentralizada de política social, realizado por meio de redes sociais estabelecidas entre a comunidade, o poder público e algumas empresas que vêm financiando inúmeros projetos culturais na favela da Mangueira. Da sinergia entre essas três forças vimos surgir, nesse contexto, um programa de desenvolvimento local e de enfrentamento da exclusão social, promovido pela Escola de Samba Estação Primeira da Mangueira e que nos parece novo na realidade carioca.

Ao longo dos quatorze anos de atuação social, o Programa passou a ter o número de 30 projetos sociais voltados aos moradores da favela e de comunidades adjacentes. Atualmente, ele envolve um grande número de empresas privadas que atuam em projetos de saúde, educação, cultura, lazer, esporte e formação profissional. Além disso, constrói parcerias com a Prefeitura Municipal do
Rio de Janeiro, os governos estadual e federal e associações comunitárias.

O Programa Social da Mangueira foi elaborado em meados dos anos 1980. O cenário político da época trazia em seu bojo o processo de redemocratização do país e o prenúncio da promulgação da nova Constituição Federal, em 1988, que envolveu a participação de grande parcela da sociedade.

As sucessivas crises econômicas, a abertura política e econômica e a mobilização da sociedade influenciaram no modelo de intervenção centralizadora do Estado nas atividades econômicas e, sobretudo, em relação às funções sociais por ele desempenhadas. Assim, a afirmação do Estado como ator central e exclusivo na implementação de programas sociais passou a ser questionada pela sociedade. Novos mecanismos institucionais - como a descentralização administrativa e a participação cidadã - foram canalizados pelo aparelho estatal para o desenvolvimento de políticas sociais em nível local.

Por outro lado, a reestruturação industrial levou muitas organizações empresariais, principalmente as de grande porte, a adotar uma nova cultura calcada na ética e na responsabilidade social. 
Baseadas no senso de "responsabilidade social", tais empresas passaram a ter a expectativa de que a implantação de ações sociais, além das previstas na legislação brasileira, e de uma gestão participativa podem aumentar a produtividade de seus empregados e torná-los mais comprometidos com o trabalho; da mesma forma, podem obter o reconhecimento da sociedade em relação aos projetos sociais das empresas preocupadas com a questão ambiental, a saúde, a educação, a cultura etc., que assumem, assim, parcelas da dívida social.

Os movimentos da sociedade civil passam a expressar-se em uma dimensão mais participativa, buscando canalizar as novas demandas sociais e obter uma legitimidade popular maior. Ao tratar da redistribuição de responsabilidades entre o Estado, a sociedade civil e o mercado, enfatizamse ações que buscam a solidariedade e a justiça social como cimento que agrega esses blocos. A cooperação e a confiança passam a fazer parte do novo processo de interação comunitária, em que se deve compartilhar democraticamente os interesses.

De acordo com essa concepção de solidariedade, considera-se que a participação ativa dos agentes sociais é capaz de potencializar as relações de cooperação entre os membros da sociedade, contribuindo para o seu desenvolvimento e compondo o chamado "capital social".

\section{RESPONSABILIDADES E NOVAS FORMAS DECULTURA POLÍTICA}

Diante da enormidade dos problemas sociais e do recuo do Estado em relação à questão social, os cidadãos e a sociedade são conclamados a compartilhar responsabilidades na resolução desses problemas. O desafio atual está em encontrar um consenso sobre o quê, quem e como se responder aos anseios da sociedade em relação ao seu bemestar, como coletividade. A questão é: que devemos fazer coletivamente - e não individualmente - para que as ações sociais resultem do envolvimento tanto da motivação individual para uma ética solidária constitutiva da coesão social, quanto da garantia da "responsividade" do Estado face aos cidadãos.

A idéia da cooperação de responsabilidades entre os setores público e privado, na realização de obras e prestação de serviços, esteve marcada por uma distinção clássica, segundo a qual o público identifica-se com o Estado e o privado com o mercado.

A concepção da ocupação do espaço público como o uso de todos e para todos remete-nos ao processo histórico da conquista dos direitos civis, políticos e sociais. No Brasil, os direitos sociais foram regulamentados por governos ditatoriais, no mesmo momento em que os direitos políticos eram suprimidos, o Legislativo era fechado ou funcionava à mercê do Poder Executivo. Como consequiência, tivemos uma supervalorização do Poder Executivo, que apontava para a onipotência do Estado frente aos interesses do público em geral (CARVALHO, 1995). Esse processo de desenvolvimento da cidadania disseminou uma cultura política estatizante, que vinculava a resolução dos problemas coletivos ao poder do Estado. Nesse sentido, tudo o que era público era estatal. Recentemente, a distinção entre o público e o privado vem sofrendo um processo de transformação. Esse processo ocorre paralelamente ao processo de construção da democracia na América Latina.

A redemocratização do Brasil e a capacidade organizativa da sociedade propiciaram um avanço nos direitos da cidadania. Aliás, o termo "cidadania" começou a ser empregado por vários setores da sociedade: agentes políticos, militantes partidários, partidos políticos, instituições religiosas, organizações não-governamentais (ONGs) e inúmeros movimentos sociais, que passaram a lutar por interesses públicos e por novas formas de organização e participação política.

Junto com as novas formas de ação coletiva vem a nova ocupação do espaço público por um conjunto diversificado de atores e associações. A iniciativa privada saiu em busca de mercados alternativos para utilização de sua capacitação empresarial, financeira e administrativa na execução dos serviços públicos, até então de competência do Estado. Acrescentou-se a tal cenário de cooperação entre o público e o privado, principalmente nas áreas metropolitanas, o desafio de fazer-se um novo desenho institucional que capte os anseios dessa nova sociedade civil. $\mathrm{O}$ cenário político-econômico forçará uma revisão das relações entre o Estado e a sociedade, criando um novo espaço, em que se manifestam os interesses dos cidadãos. Nesse espaço eles passam a desempenhar funções que antes eram da competência exclusiva do Estado, como a gestão da política social. 
Bresser Pereira e Grau apontam o fato de que a crise do Estado e a globalização exigem novas modalidades, mais eficientes, de gestão, que incluem a emergência de um espaço em que as organizações ou formas de controle público estejam voltadas para o interesse geral - o espaço público não-estatal (PEREIRA \& GRAU, 1999, p. 16-17).

Sendo assim, o conceito de espaço público nãoestatal proposto por Bresser e Grau surge para romper os limites impostos ao espaço público tradicional, limitado ao controle da esfera estatal. A responsabilidade social passa a ser compartilhada pela sociedade organizada: "O que é estatal é, em princípio, público. O que é público pode não ser estatal, se não faz parte do aparato do Estado" (idem, p. 17).

A seguir apresentaremos a busca de novas responsabilidades dos movimentos sociais, do poder público e das empresas, que passam a operar por meio de redes sob a forma de parcerias.

\section{II.1. Os movimentos sociais}

A crise fiscal do Estado, desencadeada nos anos 1970, pelo aumento do preço do petróleo, levou a uma crise do Estado de Bem-estar Social. Em seu lugar vem surgindo a expectativa um Estado promotor do bem-estar social com a função de aumentar a participação da sociedade e de compartilhar com ela a responsabilidade social, na medida em que, sozinho, não pode mais arcar com essa responsabilidade.

Em contrapartida, a sociedade civil passa a não mais esperar dos Estados a resposta única para a garantia de melhores condições de vida e bemestar para o conjunto da sociedade. A sociedade civil organizada passa a defender o interesse público e a construir novos parâmetros de coesão social e solidariedade, sobretudo a partir de seu fortalecimento como agente indutor da opinião pública.

As crises econômicas aliadas à globalização propiciaram um redesenho da luta pelos direitos humanos e sociais. Pessoas e grupos juntaram-se em busca de objetivos em comum. Surgiram as ONGs como canais não-oficiais dando apoio internacional a microprojetos sociais dirigidos para o nível local. Muitas vezes o trabalho de uma ONG não se limita a uma definição territorial e nem mesmo funcional. A orientação prioritária das ONGs tem sido a de mobilizar pessoas e ideais com interesses localizados, mas potencialmente universalizáveis, para executar ações sociais sem fins lucrativos de caráter voluntário. Da mesma forma, estão surgindo associações e fundações mobilizando cidadãos, empresas e governos para a captação de recursos visando a ações sociais. Essas novas organizações afirmam a capacidade de agir da sociedade civil, ocupando espaços nas políticas sociais antes reservados exclusivamente ao Estado (FERNANDES, 1995).

O poder antes localizado no Estado agora dá lugar à noção de poder difuso, que se estende por uma rede de relações e campos setoriais, como grupos de mulheres, jovens, aposentados, grupos étnicos, ambientalistas etc. As atividades das novas organizações, que antes ficavam distantes do poder decisório e central do Estado, passam a ser feitas por meio de parcerias, com o objetivo de garantir melhores condições de vida e bem-estar para o conjunto da sociedade, estabelecendo, assim, uma nova compreensão dos limites do Estado e da sociedade.

Essas iniciativas da sociedade civil indicam o surgimento de uma nova cultura política, uma vez que as práticas sociais são orientadas por um novo nível de condutas, normas e valores em relação ao interesse público (AVRITZER, 1995).

Porém, nem todos os movimentos da sociedade civil têm impactos positivos para a sociedade. Muitos deles têm relação negativa com o restante da sociedade e tendem a resistir a inovações que produzam o bem-estar. Muitos desses movimentos mostram-se altamente não-cívicos, como o preconceito racial da Ku-Klux-Klan, os de caráter para-militar, as famílias da Máfia, as redes de prostituição, turmas de jovens (PORTES \& LANDOLF, 1996; REILLY, 1999, p. 425) e até mesmo o tráfico organizado de drogas.

Além disso, muitos movimentos da sociedade civil possuem um caráter conservador, produzido por atores sociais que partem de sua identidade cultural para discriminar os demais. São movimentos segregacionistas, que Castells (1999) define como a "exclusão dos que excluem pelos excluídos", ou seja, são movimentos que constroem uma identidade defensiva que reverte o julgamento de valores, ao mesmo tempo em que reforçam os limites de resistência (fundamentalistas religiosos, nacionalistas exaltados, movimentos contrários ao homossexualismo etc.). 
A despeito do associativismo negativo, constata-se o aumento do número e do ritmo de associações que atuam em torno de temas como os direitos humanos, os direitos da mulher, a ecologia, a paz mundial etc., que constituem um avanço significativo da participação da cidadania no processo de democratização (AVRITZER, 1997).

Ainda que tenha havido uma renovação na dimensão organizativa da sociedade, reconhecese também que em muitos casos, em especial no Brasil, não ocorreu o rompimento de uma herança histórica caracterizada pelo reduzido número de associações (idem). Ainda é necessário um tempo de aprendizado para que essas formas de associativismo sejam capazes de ampliar a utilização dos direitos civis e, por sua vez, fortalecer seus direitos políticos, modificando, assim, a sua cultura política participativa (CARVALHO, 1995).

No momento, muitas dessas organizações aprendem a lidar com a luta pelos direitos sociais. Buscam modelos mais eficientes de políticas sociais para ampliar seu raio de ação e legitimidade frente à sociedade, com o objetivo de intervir no alívio da pobreza, na garantia dos direitos humanos fundamentais e na eliminação das desigualdades sociais.

\section{II.2. A governança como nova forma de gestão estatal}

A discussão contemporânea sobre o novo Estado tem sido direcionada para os requisitos políticos, sociais, organizacionais e gerenciais que tornem o Estado eficaz e eficiente, para ser capaz de enfrentar os desafios que se impõem e os dilemas que se apresentam.

Constata-se que a crise fiscal do Estado acabou influenciando a credibilidade pública do Estado, enfraquecendo a percepção de sua finalidade e legitimidade diante da ineficiente administração dos problemas. A crise foi captada, interpretada e direcionada contra o Estado, gerando um abalo na confiança em relação à sua operacionalidade. As idéias neoliberais passaram a ter força na medida em que houve a ruptura de um pacto de solidariedade, que fundamentava o Estadoprovidência e funcionava como uma espécie de sociedade securitária para organizar a segurança de todos e compensar as disparidades de status social (ROSANVALLON, 1998).

A crítica ao papel do Estado, corrente nos anos
1970 e 1980, passam a ser reconceitualizadas nos anos 1990. Ao mesmo tempo em que houve a aplicação de políticas de ajuste, diminuindo o papel do Estado como ator responsável pelo bem-estar social, não houve medidas para a eliminação da pobreza e a minimização das desigualdades sociais, que se acentuaram.

No debate dos anos 1990 acerca da redefinição das funções do Estado, surgiu a concepção de "governança" (governance). O termo pretende ampliar o conceito estritamente econômico de "gestão pública", para alcançar uma visão mais abrangente que envolva, interdisciplinarmente, as dimensões econômica, política e social, no sentido de aumentar a capacidade do governo.

O novo modelo de atuação do Estado pressupõe, sinteticamente, que não se substitua a sociedade civil nem o mercado, mas que o Estado atue em conjunto com ambos, como um elemento de apoio, entendido assim como um Estado fomentador de iniciativas de ações sociais (DINIZ, 1995).

A governança consiste no estabelecimento de um sistema de normas inseridas em um redesenho estratégico que envolve a participação de variados atores sociais (ONGs, associações, mercado) que compartilham da capacidade governativa do Estado, na identificação dos problemas da sociedade e na formulação de políticas públicas e na sua implementação (DINIZ,1997).

O termo "governança" foi introduzido no debate público internacional pelo Banco Mundial, que deu ao conceito um caráter prescritivo. Outras agências multilaterais, como o Fundo Monetário Internacional, passaram a legitimar suas orientações por esse conceito1. A noção de "boa governança" (good governance), do Banco Mundial, vem intrinsecamente associada à capacidade governativa e passou a ser requisito indispensável para um desenvolvimento sustentável, que incorpora ao crescimento econômico a eqüidade social e os direitos humanos (WORLD BANK, 1992, p. 1).

Reconhecer o debate sobre governança

\footnotetext{
1 Para o Banco Mundial, a definição de governance consiste "na maneira pela qual o poder é exercido na gestão dos recursos econômicos e sociais de um país com vistas ao desenvolvimento" (WORLD BANK, 1992, p. 1-3).
} 
significa relacionar o bom desempenho governamental à participação cívica dos grupos sociais que controlam o processo ou partes do processo de que resultam ações de seu interesse, cabendo então ao próprio Estado fortalecer a sociedade e dar curso às suas aspirações.

O modelo de descentralização das políticas sociais aparece como estratégia inovadora para revigorar o Estado e minimizar a crise de gestão quanto à ineficiência das políticas públicas, valorizando poderes locais e promovendo a participação dos cidadãos na gestão pública. Assim, os elementos da agenda de reforma assumem novos significados. $\mathrm{O}$ processo de descentralização confunde-se com o processo de redemocratização, notadamente nas áreas de saúde, educação e assistência social.

Outra questão ligada à descentralização é o que Norbert Lechner chamou de "coordenação social por meio de redes" (LECHNER, 1997, p. 12). O autor vê essa possibilidade como uma alternativa fundamental para os países em desenvolvimento formularem políticas sociais inclusivas. Essa questão leva-nos a um novo conceito, crucial para a compreensão de gestão pública descentralizada: o conceito de "redes" (networks).

O trabalho em redes, além de possibilitar a adequação dos planos de desenvolvimento - do Estado e de agências de fomento e financiamento -, beneficia as empresas, que podem reduzir os custos das transações por meio de laços cooperativos e de confiança entre agências públicas e privadas (SKIDMORE, 2001).

Assim, entende-se pela expressão "rede" um arranjo organizacional composto por vários indivíduos ou instituições vinculados a um projeto específico. A coordenação dos interesses individuais e coletivos, em rede, requer contínuas negociações que não se limitam a uma troca de benefícios entre os participantes. Portanto, o desafio está em coordenar as diversas percepções em relação aos fins e aos meios das ações dentro da rede.

É nesse contexto de reconstrução das relações entre Estado e sociedade, em que surgem as redes de parcerias para a gestão de políticas sociais, que este artigo focaliza sua atenção.

\section{II.3. Responsabilidade social empresarial}

Quanto à perspectiva de que capital social é promovido pela ampliação da participação de diversos agentes sociais em favor do desenvolvimento, temos observado no Brasil que novas redes de participação vêm sendo articuladas. Constata-se um movimento de solidariedade de alguns setores do empresariado brasileiro, visando à mobilização de recursos, ao intercâmbio de experiências e à formulação de projetos sociais fundados em identidades e valores coletivos.

Sob pressões advindas do sistema internacional, que redefiniu a agenda governamental nos anos 1980 e 1990, o empresariado brasileiro vem tendo que se adaptar ao seu novo papel político e social, definido a partir da reestruturação industrial. Novos canais de participação criam-se à margem da estrutura corporativa oficial.

Por exemplo: o PNBE (Pensamento Nacional das Bases Empresarias) - fundado em 1987 e que no ano 2000 contava com 480 empresários de São Paulo, Rio de Janeiro, Brasília, Fortaleza, Campinas, Ribeirão Preto, Vitória e Presidente Prudente - surgiu no patamar dessa reordenação ideológica empresarial. O PNBE apresenta uma forte inclinação para a ação social e uma nova postura frente ao sistema político e tem combatido a oligarquização e o imobilismo que marcaram a cultura empresarial das décadas anteriores (GOMES \& GUIMARÃES, 1999).

$\mathrm{O}$ maior divulgador das questões ligadas à responsabilidade social no Brasil é o Instituto Ethos de Responsabilidade Social Empresarial, uma organização sem fins lucrativos fundada em 1998. O Instituto Ethos tem os mesmos propósitos da similar americana BSR (Business for Social Responsibility), que conduz projetos e programas em nível global, buscando incentivar empresas a alcançar sucesso em seus negócios implementando práticas que respeitem pessoas, comunidades e o meio ambiente. Criado no Brasil pelos representantes do movimento empresarial do PNBE, o Instituto Ethos acredita que investir em responsabilidade social é um grande negócio, na medida em que as empresas podem compartilhar custos com o governo em relação ao desenvolvimento sustentável local, por meio de uma rede de ações capazes de sensibilizar, motivar e facilitar o investimento social dos empresários brasileiros: "A comunidade em que a empresa está inserida fornece-lhe infra-estrutura e o capital social representado por seus empregados e parceiros, contribuindo decisivamente para a viabilização de seus negócios. O investimento pela empresa em 
ações que tragam benefícios para a comunidade é uma contrapartida justa, além de reverter em ganhos para o ambiente interno e na percepção que os clientes têm da própria empresa" (INSTITUTO ETHOS, 2000; sem grifos no original).

Submetidas à concorrência internacional, as empresas passaram a buscar soluções para melhorar seu desempenho e sua competitividade. $\mathrm{O}$ aumento da competição internacional impôs novos padrões de desempenho produtivo, tecnológico e mercadológico às empresas. Foi necessária uma adaptação às novas necessidades, como uma produção mais flexível; trabalhadores mais qualificados ou multiespecialistas; integração entre trabalhadores e máquinas, além de tecnologias avançadas.

Por sua vez, o processo de consolidação democrática, proteção e defesa do consumidor, bem como a defesa do meio ambiente, tornaram o consumidor e o público em geral muito mais exigentes com a qualidade dos produtos e serviços que lhes são oferecidos.

A qualidade do produto e a qualidade gerencial são hoje fatores competitivos essenciais para conseguir-se atrair clientes, produzir mais e reduzir os custos. Da mesma forma, a competitividade do mercado tem exigido uma alteração na mentalidade do empresariado, com uma ênfase maior na perspectiva que focaliza o fator humano e social como chave para o sucesso.

$\mathrm{Na}$ medida em que as regras da operação dos negócios foram tornando-se obsoletas, a sobrevivência das empresas passou a depender de sua capacidade de aceitar as novas idéias e estratégias de organização empresarial.

Contudo, nem todas as empresas estão mudando. Aquelas que mudam, em especial as grandes empresas, têm apontado para o fato de que a resistência à mudança é resultado da acomodação gerencial, da falta de perspectivas na mudança ou da insegurança provocada pela ausência de treinamento e educação voltados às novas práticas.

Os movimentos sociais, em especial os ambientalistas, conquistaram uma posição de destaque nessa nova configuração empresarial. Muitas empresas de grande porte, inclusive as responsáveis pela emissão de poluentes, passaram a incluir em sua agenda a questão ecológica. Considera-se uma empresa ambientalmente responsável aquela que age para a manutenção e melhoria das condições ambientais, minimizando ações próprias potencialmente agressivas ao meio ambiente e disseminando em outras empresas as práticas e conhecimentos adquiridos nesse sentido.

Algumas empresas têm adotado códigos de ética que abrangem condutas de empregados, relações com a comunidade e o ambiente, fornecedores e prestadores de serviços, atividade política e tecnologia. Essas empresas passaram a ter duas metas dentro de suas estruturas éticas: obter vantagem competitiva e alcançar legitimidade empresarial. A legitimidade empresarial provém de metas, propósitos e métodos consistentes com os da sociedade. Assim, as organizações devem ser sensíveis às expectativas e aos valores da sociedade.

A questão da ética nos negócios tem sido valorizada, atualmente, em muitas grandes empresas, no meio acadêmico e nos meios de comunicação. A ética corporativa guia-se por valores ou princípios de conduta como honestidade, justiça, integridade, respeito, transparência, respeito pelo outros e cidadania responsável.

Recentemente se vem falando de "responsabilidade social empresarial", que pode ser definida como uma gestão administrativa direcionada para a implantação de ações sociais que beneficiem o público interno da empresa (funcionários e dependentes, fornecedores e parceiros dos negócios) e externo (a comunidade).

A empresa que atua de maneira responsável nas dimensões interna e externa, sem se ater apenas aos resultados financeiros do balanço econômico, exercita sua cidadania empresarial e será classificada como "empresa-cidadã" pelo mercado (MELO NETO \& FROES,1999). Contudo, a ação empresarial definida como responsável não se refere ao simples cumprimento das obrigações legais, previamente determinadas pelas conquistas da sociedade.

Como explicam Cheibub e Locke (2000, p. 2), não faz sentido denominar de responsabilidade social empresarial o cumprimento da lei: "Da mesma forma, não podemos chamar de responsabilidade social as ações, programas, benefícios etc. que foram adotados pelas empresas como resultado de negociação trabalhista (acordo, convenção etc.). Nesse caso, estamos diante de uma questão de poder, barganha política, e não de responsabilidade social". 
Melo Neto e Froes (1999) salientam que a responsabilidade social deve ser vista também como um fator competitivo que contribui de maneira decisiva para o desempenho e a autopreservação das empresas. Ao investir em projetos sociais, as empresas poderão desenvolver um planejamento estratégico de propaganda social com significativos ganhos.

A responsabilidade social, então, passa a ser do interesse de algumas empresas, na medida em que, além de terem seu poder fortalecido como promotoras de bem-estar social, contribuirão para o fortalecimento da sociedade civil.

É exatamente esse o tipo de sociedade que mais atende às necessidades das empresas na economia contemporânea, isto é, uma sociedade que permite os fluxos de informações serem ágeis, diversificados e desenvolvidos para facilitar o consenso, as negociações e minimizar os custos das transações comerciais (CHEIBUB \& LOCKE, 2000; SKIDMORE, 2001).

Enfim, valores culturais novos estão surgindo no mundo corporativo brasileiro e são direcionados para a elaboração de estratégias que focalizem a excelência dos produtos e serviços, índices cada vez maiores de produtividade e a superação da concorrência. Além disso, o empresariado está aderindo à idéia da cooperação com o poder público para buscar benefícios mútuos e oferecer algo mais à sociedade, além de produtos e serviços: respeito e credibilidade.

\section{A RELAÇÃO ENTRE DESENVOLVIMENTO E CAPITAL SOCIAL}

A importância dada ao tema do desenvolvimento econômico e social para os países em desenvolvimento, em particular o Brasil, pode ser explicada se levarmos em conta o fato de que os mercados e os Estados-nação, ao cabo dos anos 1990, não estiveram mais insulados em seus próprios setores. A crise do Estado, os altos índices de inflação, a adoção de políticas de ajuste, a globalização, o desemprego, o acentuado empobrecimento da população e o aumento das desigualdades sociais influenciaram a vida dos indivíduos e da sociedade de maneira geral. Surgiu o desafio de enfrentar a pobreza e a injustiça social.

O crescimento econômico do mundo industrializado, calcado historicamente na produção, passou a ser questionado por grupos sociais e, principalmente, pelas agências internacionais de desenvolvimento. Novas formulações enfatizaram a necessidade de uma integração entre a diversidade cultural, o desenvolvimento econômico e o desenvolvimento humano, diante do aumento da pobreza e das desigualdades sociais.

O Prêmio Nobel de Economia de 1998, Amartya Sen, compartilha esse entendimento, definindo o desenvolvimento como um processo contínuo que leva à implementação de liberdades substantivas, que ele chama de "entitulamentos" (entitlement) econômicos, garantia de transparência, segurança protetora e oportunidades sociais (SEN, 1999).

Amartya Sen aponta duas visões antagônicas de desenvolvimento. A primeira delas sustenta que o desenvolvimento é um processo violento, sofrido, envolvido inevitavelmente em "sangue, suor e lágrimas" e em que o desafio de acumular riquezas o mais rapidamente possível pode levar ao sacrifício do bem-estar (idem, p. 51). O autor repudia essa concepção e mostra a existência de outra corrente, para a qual o desenvolvimento é um processo "essencialmente amigável" e pode ser exemplificado por meio das trocas benéficas, do trabalho de redes de segurança social, pelas liberdades políticas ou pelo desenvolvimento social - ou uma ou outra combinação destas atividades de apoio (idem, p. 52).

Sendo o desenvolvimento o aumento da capacidade dos indivíduos fazerem escolhas, é preciso definir o que é liberdade de escolha: a liberdade não é a ausência de restrições, o direito abstrato de ir, vir, comprar, vender. Não se pode pensar a liberdade - e, portanto, o desenvolvimento - fora das condições concretas de seu exercício. Não basta que a lei garanta certos direitos: o essencial é que os indivíduos tenham as capacidades, as qualidades, as prerrogativas de deslocar-se, de participar dos mercados e de estabelecer relações humanas que enriqueçam sua existência.

Nesse sentido, o desenvolvimento é essencialmente uma estratégia de ações inter-relacionadas, em que a natureza do processo de desequilíbrio é superada por um equilíbrio na trajetória das principais variáveis econômicas e sociais: "Nessa perspectiva, as pessoas têm de ser vistas como ativamente envolvidas [...] na conformação de seu próprio destino, e não apenas como beneficiárias passivas dos frutos de engenhosos programas de 
desenvolvimento. O Estado e a sociedade têm papéis amplos no fortalecimento e na proteção das capacidades humanas. São papéis de sustentação e não de entrega sob encomenda. A perspectiva de que a liberdade é central em relação aos fins e aos meios do desenvolvimento merece toda a nossa atenção" (idem, p. 71).

Agrega-se a essa visão ampla de desenvolvimento o conceito de "desenvolvimento sustentável". A expressão foi cunhada pela Comissão Mundial sobre Meio Ambiente e Desenvolvimento (Comissão Brundtland) em 1987. Ao defender um desenvolvimento que "atenda às necessidades da geração atual sem comprometer as necessidades das gerações futuras", o relatório da Comissão Brundtland destacava a necessidade de satisfazer simultaneamente os imperativos do desenvolvimento e do meio ambiente (SERAGELDIN, 1993) $)^{2}$.

Nessa época, o Banco Mundial passou a adotar o conceito de desenvolvimento sustentável compreendendo-o como um conceito que combina três disciplinas: (a) a Economia, ao maximizar o bem-estar humano dentro das limitações do estoque de capital e das tecnologias disponíveis; (b) a Ecologia, ao enfatizar a preservação da integridade dos subsistemas ecológicos, considerados fundamentais para a estabilidade do ecossistema global e (c) a Sociologia, ao enfatizar os seres humanos enquanto atores principais cujo padrão de organização social é fundamental na busca de estratégias viáveis para o desenvolvimento sustentável.

Combinando as três áreas do conhecimento, o projeto de desenvolvimento sustentável estará atrelado à participação e ao envolvimento da sociedade, bem como à utilização de metodologias que tenham por base os impactos na saúde humana, nos bens produtivos e nas funções ecológicas. A intenção consiste em produzir o aumento de renda sem comprometer o meio ambiente e a qualidade de vida das pessoas.

Em uma vertente contrária à do Banco

\footnotetext{
2 Nesse artigo Serageldin, na época vice-Presidente da área de Desenvolvimento Ecologicamente Sustentável, criada pelo Banco Mundial, destaca a necessidade de ampliarmos nosso conceito de desenvolvimento, integrando os enfoques dos sociólogos, dos ecologistas e dos economistas.
}

Mundial, encontra-se Stephen Tindale (1994), que apresenta questões fundamentais a respeito do desenvolvimento sustentável como um desafio ao projeto político da esquerda.

O autor relaciona a democracia social ao desenvolvimento sustentável, no sentido de conseguir-se o nível máximo possível de atividade econômica e geração de riqueza dentro da estrutura ecológica, ligando a igualdade e a condição futura em função das preocupações em relação à saúde e à sobrevivência daqueles que mais sofrem à degradação de recursos e poluição - as populações mais pobres.

Enfim, a sustentabilidade deve ser "construída socialmente", ou seja, é de suma importância buscar-se acordos de natureza social, econômica e ecológica, além de propiciar um conjunto de técnicas sociais capazes de induzir à ação social coordenada e ajudar no desenvolvimento de capital social, criando grupos e associações no sentido de priorizar as pessoas e conceber estratégias envolvendo os atores sociais: "Níveis mais elevados de organização social adequada resultam em maior bem-estar, sustentabilidade social para os programas de desenvolvimento e melhor gestão do meio ambiente" (CERNEA, $1993)^{3}$.

Comumente os economistas e as agências multilaterais reconhecem três formas de capital, ou seja, três formas de ativos que produzem riqueza e desenvolvimento: a) o capital físico natural, constituído pelos recursos naturais de um país; b) o capital construído pelo homem, que inclui a infra-estrutura, o capital financeiro, comercial etc.; c) nos anos 1970-1980 incluiu-se o capital humano, referindo-se às habilidades, conhecimentos e criatividade com que os indivíduos contribuem para a vida econômica (KLIKSBERG, 1999).

Mais recentemente surgiu a sensibilidade quanto ao potencial de produção de riqueza e desenvolvimento, que flui das várias formas de associação coletiva: o capital social. Esse capital refere-se aos laços de confiança, de compromisso, de vínculos de reciprocidade, cooperação e solidariedade, capazes de estimular normas,

\footnotetext{
3 Michel Cernea é Assessor Sênior do Banco Mundial em Políticas Sociais e Sociologia, no Departamento de Meio Ambiente.
} 
contatos sociais e iniciativas de pessoas para aumentar o desenvolvimento humano e econômico.

O capital social será tanto mais forte quanto mais permitir a ampliação do círculo de relações sociais em que vivem aqueles que participam de sua construção. Essa visão é inteiramente compatível com a definição de desenvolvimento proposta por Amartya Sen, na medida em que a sociedade não é vista como a soma de indivíduos agindo de maneira independente uns dos outros e coordenando suas ações por meio de um instrumento supostamente neutro - o mercado.

O capital social tem sido identificado como um componente integral do desenvolvimento econômico e social, que molda a quantidade e a qualidade das interações sociais de uma sociedade. Reconhecendo o potencial desse conceito, o Banco Mundial vem-no usando para investigar e analisar como e de que forma o capital social habilita os pobres a participarem ativamente e a beneficiarem-se do processo de desenvolvimento.

O termo "capital social" foi definido independentemente por Pierre Bourdieu e por James Coleman nos anos 1980, como laços sociais que possibilitam vantagens e oportunidades a indivíduos e comunidade. A análise de Bourdieu focaliza os benefícios que resultam em virtude da participação dos indivíduos em grupos e o papel que a sociabilidade pode trazer aos indivíduos. O sociólogo definiu capital social como "o agregado de recursos reais ou potenciais que são ligados ao domínio de uma rede permanente de conexões institucionais de habilidades ou reconhecimento mútuos".

Coleman ${ }^{4}$ (1988) também usou o termo para descrever os recursos dos indivíduos que emergem de seus laços sociais. Usou como exemplo os comerciantes de diamantes judeus de Nova Iorque para ilustrar o conceito: eles podiam comercializar por meio de suas redes locais sem a

\footnotetext{
4 Coleman definiu capital social por sua função como "a variety of entities with two elements in common: they all consist of some aspect of social structures, and they facilitate certain action of actors - whether persons or corporate actors - within the structure" ["uma variedade de entidades com dois elementos em comum: todos eles consistem em alguns aspectos de estruturas sociais e facilitam certas ações dos atores - sejam atores pessoais ou corporativos - na estrutura" - Nota do revisor].
}

necessidade de recorrer a contratos comerciais caros (PORTES \& LANDOLF, 1996).

Para Coleman, o capital social é criado por indivíduos racionais que atuam livremente para construir o capital social que maximizará suas oportunidades sociais e econômicas. O componente-chave da definição de Coleman é a confiança entre os indivíduos que fazem parte do mesmo círculo estreito de relações. Essa confiança reduz os custos das transações entre eles (COLEMAN, 1987).

A partir da definição de Coleman, outros importantes teóricos da década de 1990 descreveram a importância que o capital social pode trazer para as possibilidades de avanço democrático.

A principal referência sobre capital social é a de Robert Putnam (1996). Em seu estudo comparativo sobre o desenvolvimento político das regiões da Itália estabeleceu uma conexão entre o grau de civismo de uma comunidade e a qualidade de sua governança. Para o autor, a raiz do maior desenvolvimento do Norte italiano encontra-se nas organizações que datam de quase mil anos atrás, como os coros de Igreja e as sociedades de ajuda mútua baseadas no associativismo horizontal e com alto grau de participação cívica. O capital social refere-se ao conjunto de normas de confiança mútua, às redes de cooperação, aos mecanismos de sanção e às regras de comportamento que podem melhorar a eficácia da sociedade na solução de problemas que exigem a ação coletiva. O capital social seria, pois, um bem público, um verdadeiro subproduto de outras atividades sociais, fundado em redes horizontais e nas relações de confiança.

Putnam relaciona a tradição cooperativa e os laços de solidariedade horizontal e de confiança com o melhor desempenho institucional das regiões situadas ao Norte da Itália. Na região Sul predominariam as relações verticais, caracterizadas pela concentração de poder de proprietários de terra, menor participação social, incapacidade de os indivíduos agirem coletivamente e maior alocação de oportunidades individualistas. Tal fato explicaria o atraso e as maiores desigualdades sociais dessa parte da Itália.

Os argumentos de Putnam foram criticados por Portes e Landolf (1996) como inconsistentes ao explicar o sucesso ou o fracasso de uma comunidade. Para os autores a situação de pobreza 
de alguns grupos urbanos não é resultado da falta de capital social ou de sua falta de civismo ${ }^{5}$ e sim da falta de recursos econômicos concretos.

Como bem mostra a síntese recente de AbuEl-Hay sobre capital social (1999, p. 71), o ponto de vista de Putnam acaba sendo de profundo ceticismo, quando associa as possibilidades de avanço democrático à existência de ingredientes culturais naturais a certas sociedades.

O cientista político Peter Evans (1996), procurando representar uma alternativa neoinstitucionalista à visão "culturalista" de Putnam, enfatizou o papel decisivo da burocracia estatal na formação de capital social, no sentido de que a função do Estado passaria da ação reguladora da interação social para a de indutor e mobilizador do capital social, ligando cidadãos e mobilizando as agências públicas a aumentarem a eficiência governamental, a partir de uma sinergia entre o Estado e a sociedade civil como um conjunto de relações que ultrapassa a divisão público-privado.

Evans questiona a possibilidade de essa sinergia depender primariamente de dotes sócio-culturais preexistentes e com origens históricas. Se assim fosse, muitas culturas seriam deixadas de lado e experiências satisfatórias têm mostrado que o importante é a interação entre iniciativas de políticas sociais do Estado e a mobilização social, a partir do patrocínio de um Estado reformista. Para o autor, a sinergia fracassa quando não é forte o engajamento das instituições públicas. Nesse sentido, a sinergia entre Estado e sociedade pode criar um círculo virtuoso de mudança institucional.

A idéia de Evans - de que redes de engajamento cívico entre cidadãos podem ser promovidas por agências públicas - tem substancial relação com o trabalho desenvolvido anteriormente por Judith Tendler (1998) sobre o "bom governo" no Nordeste brasileiro.

\footnotetext{
5 Portes e Landolf criticam os argumentos de Putnam por os considerar sustentados por um raciocínio tautológico, quando explica que o fracasso ou o sucesso de uma comunidade identificam-se com a presença ou ausência de capital social: "The very concept of citizenship is stunted here: 'If your is 'civic', it does civic things; if it is uncivic', 'it does not"” ["o próprio conceito de cidadania está truncado aqui. 'Se o seu é 'cívico', ele faz coisas cívicas; se ele é 'incívico', ele 'não faz coisas cívicas'” - N. R.].
}

Nesse trabalho citado por Evans, a autora analisa diversos programas pioneiros desenvolvidos pelo governo estadual do Ceará, no período de 1992 a 1996, para o combate à pobreza. Os casos analisados por Tendler revelaram que o governo pode ser uma presença moral forte para a criação de capital social. Diversas ações voltadas para o desenvolvimento econômico e de capital humano e assistência social tiveram resultados positivos na formação de associações cívicas para a melhoria do desempenho local, tais como: 1) realização de campanhas públicas de informação; 2) insistência em fornecer serviços apenas por meio de associações de produtores e não por indivíduos ou empresas isoladas, e em trabalhar com esses grupos por mecanismos que faziam as vezes de contrato e 3) exigência de discussão formal sobre decisões a respeito do investimento público nos municípios por meio de conselhos municipais que, por insistência do governo estadual, incluíssem representantes da sociedade civil e do governo estadual (1998, p. 206).

Em suma, ambos autores convergem para a mesma questão: o capital social não é simplesmente um atributo cultural cujas raízes só podem ser fincadas ao longo de muitas gerações. Ele pode ser criado - desde que haja organizações suficientemente fortes para sinalizar aos indivíduos alternativas aos comportamentos políticos convencionais.

Trabalhar com o conceito de capital social é desafiador pois engloba outros, como "confiança", "solidariedade" e "redes". O desafio aumenta quando a questão de medir não está apenas na quantidade mas também na qualidade de capital social em variadas escalas.

O presente trabalho abrange uma concepção de capital social que supõe que:

1) relações horizontais de participação, cooperação, confiança e solidariedade contribuem para a criação e/ou o fortalecimento do capital social da sociedade e, conseqüentemente, facilitam o desenvolvimento do bem-estar da coletividade;

2) a participação coletiva é elemento fundamental do capital social de uma sociedade, sendo de vital importância a existência de regimes políticos democráticos capazes de dotar o Estado de uma cultura democrática, que crie instrumentos favoráveis ao acesso às 
informações sobre os negócios públicos e o controle da sociedade.

3)o legado do autoritarismo contribui para tornar as relações sociais de reciprocidade e confiança silenciosas e/ou invisíveis. Cabe ao Estado democrático promover ações criativas que induzam à otimização dessas relações, por meio da sinergia entre governo, comunidade e mercado. Assim, o capital social aumentará e poderá contribuir para a autonomia da sociedade na garantia de seu bem-estar social e;

4)entendemos que o capital social não é o quesito único e máximo para o desenvolvimento de uma sociedade. O bem-estar econômico e social é resultado da combinação de indicadores de condições naturais e ambientais; das condições de acesso à saúde e conhecimento; do acesso a recursos monetários e às condições de acesso ao trabalho. Logo, a interação do capital social com as demais formas de capital (natural, humano e financeiro) pode influenciar positivamente no desenvolvimento amplo da sociedade.

Em nosso estudo de caso sobre o Programa Social da Mangueira buscamos verificar a ação do capital social da comunidade da Mangueira, a partir das novas formas de gestão social descentralizadas na cidade do Rio de Janeiro desde 1987.

Como os projetos sociais da favela da Mangueira surgiram a partir da Escola de Samba da Mangueira, tendo o samba como principal fenômeno agregador desses projetos, julgamos importante adotar o conceito de capital social de Putnam (1996), na medida em que o autor define o capital social como o produto de vida social e política vibrante de uma comunidade cívica. E, como veremos a seguir, a trajetória da Mangueira associa-se a uma cultura cívica comunitária agregadora e solidária.

A Escola de Samba da Mangueira, como organização fomentadora de ações sociais na favela da Mangueira, possui um papel de suma importância para a comunidade. Como afirmou o ex-Presidente da Escola, em 2000: “A Mangueira trabalha para o país. Tarefas que deveriam ser feitas pelos governantes são realizadas pela Mangueira" (Istó́, 2000).

Nesse sentido, a perspectiva de capital social de Peter Evans (1996) auxilia-nos, na medida em que o autor focaliza a importância de um agente mobilizador, dotado de forte engajamento político e capaz de criar um círculo virtuoso para a execução de políticas sociais. No caso de Evans esse agente é o Estado. Porém, nas devidas proporções, a Escola de Samba parece substituir o Estado no imaginário social da comunidade lembrando, inclusive, a idéia de Wanderley Guilherme dos Santos (1993) de que, no Brasil, pelo fato de o Estado ser excludente, cria-se um estado de natureza em sentido hobbesiano, em que cada qual administra seus problemas por sua própria conta.

\section{OCAPITAL SOCIAL EM AÇÃO NA FAVELA DA MANGUEIRA}

Com o intuito de resgatar traços culturais da favela da Mangueira, iniciaremos esta parte com algumas evidências do espírito solidário da comunidade, no sentido de identificar a origem da formação do capital social encontrado por meio dos projetos sociais, apresentados na seqüência.

Embora a ocupação da favela da Mangueira date do século XIX, o adensamento populacional efetivou-se a partir dos anos 1930. A Mangueira ${ }^{6}$ é uma comunidade de baixa renda que cresceu com uma população de gente pobre, constituída quase na totalidade por negros, filhos e netos de escravos - ou seja, elementos da camada dos desprivilegiados social e economicamente.

Na Mangueira a cultura cívica surgiu em torno de manifestações artísticas, culturais e esportivas. A organização social partiu do carnaval, que era o espaço em que havia maior grau de liberdade e que possibilitava levar à cidade o que durante $o$ ano ocorria na comunidade. Os blocos e as rodas de samba eram comuns na comunidade, e a Escola de Samba foi fundada em 1928. Mais tarde foi criado o Esporte Clube Cerâmica, por iniciativa do administrador da Fábrica Cerâmica Brasileira, localizada no morro, e que contou com a colabo-

\footnotetext{
6 A favela da Mangueira localiza-se no bairro da Mangueira, na zona central da cidade do Rio de Janeiro. Ela é constituída pelas comunidades dos morros da Mangueira, do Chalé, do Parque Candelária e dos Telégrafos, denominados de Complexo da Mangueira - a nona maior favela do Rio de Janeiro. Sua população é de 17860 pessoas, correspondendo a aproximadamente 4000 famílias. Dados da Mangueira e da Escola de Samba da Mangueira podem ser obtidos no sítio http://www. mangueira.com.br.
} 
ração dos moradores. O campo de futebol, além de para torneios, era utilizado para os ensaios da escola de samba e outras festividades comunitárias.

Com a fundação da Escola de Samba da Mangueira no final dos anos 1920, criou-se um espaço de sociabilidade em torno do desfile de carnaval e dos membros da favela da Mangueira. Mesmo existindo precariedade de recursos materiais, a música - em especial o samba - foi um grande incentivo à integração dos membros da comunidade, que encontram nos laços de solidariedade uma possibilidade de minorar os efeitos das difíceis condições de vida.

A comunidade da Mangueira ficou mundialmente conhecida por sua Escola de Samba. Hoje é consenso que a favela da Mangueira, a partir de sua Escola de Samba, é o celeiro e patrimônio da cultura popular e berço de alguns poetas mais geniais da música brasileira? ${ }^{7}$.

Foi por meio de sua marca cultural que a Escola de Samba da Mangueira expressou seu poder político, mobilizando segmentos da sociedade para a implantação de melhorias na qualidade de vida da comunidade. A identidade com o carnaval, o samba e a música tem contribuído para a proximidade e o diálogo com diversos setores da sociedade: artistas, intelectuais e setores das camadas médias da sociedade, incluindo turistas de outros estados e países.

O ambiente de solidariedade, aliado à forte identidade cultural de seus membros na busca de um objetivo comum, lançou as bases do estoque de capital social da comunidade.

Com o propósito de verificar a relação entre capital social e nível de associativismo na comunidade da Mangueira, buscamos dados levantados pela Pesquisa sócio-econômica de comunidades de baixa renda (PSECBR) (SCIENCE, 2000). Conforme Putnam (1996), as associações engendram hábitos cívicos e espírito de cooperação e solidariedade na sociedade. $\mathrm{O}$

7 Entre eles Cartola e Carlos Cachaça, que nasceram e foram criados nessa comunidade e depois se tornaram expoentes do samba no Brasil. Além disso, desde o início a Mangueira convive com músicos atraídos pelo samba, como Heitor Villa-Lobos, Noel Rosa e Tom Jobim; hoje continua associativismo favorece os valores cívicos, na medida em que a forma de relação entre os diversos grupos organizados pode criar efeitos benéficos para o desenvolvimento social, político e econômico de dada comunidade.

Com relação a essa dimensão, a PSECBR mostrou que nas comunidades da Mangueira apenas cerca de $18 \%$ de seus moradores declararam-se associados a algum órgão comunitário. Apesar de a porcentagem de associativismo ser baixa, isso não significa que não haja um nível significativo de sociabilidade e mesmo de laços sociais mais densos que se desenvolvem na Mangueira.

A Tabela 1 mostra a correlação dos diferentes índices de associativismo e uma tendência a diferentes formas de associativismo nas favelas. A associação a órgãos comunitários de bairro nas três comunidades pesquisadas é a forma mais comum de participação comunitária. Os altos percentuais apresentados pelas três comunidades analisadas podem ser atribuídos ao papel desempenhado nos últimos vinte anos por esse tipo de associativismo. Entretanto, em relação à comunidade da Mangueira observa-se um percentual menor em comparação às duas outras comunidades (66\% na Mangueira, contra 97\% nas favelas do Vidigal e do Jacarezinho). Essa variação pode ser explicada pelo fato de na Mangueira a associação de moradores não ser o principal intermediador nem o elo de ligação quase exclusivo entre o mundo externo e os moradores da favela, na medida em que existe a Escola de Samba da Mangueira cumprindo fortemente esse papel.

A PSECBR também aponta um diferencial bastante expressivo da comunidade da Mangueira quanto à filiação a órgãos comunitários ligados à cultura. Podemos inferir que esse dado indica que a identidade associativa da comunidade passa pelos laços culturais estabelecidos pela presença da Escola de Samba da Mangueira, em virtude de seu forte apelo cultural e artístico, evidenciando, assim, uma diferença grande em comparação com as demais comunidades pesquisadas, que não possuem tal instituição.

atraindo grandes nomes da música popular brasileira: Caetano Veloso, Gilberto Gil, Chico Buarque - apenas para citar alguns dos exemplos vivos de sua história. 
TABELA 1 - NÚMERO DE PESSOAS QUE PARTICIPAM DE ÓRGÃOS COMUNITÁRIOS

\begin{tabular}{|l|c|c|c|}
\hline & $\begin{array}{c}\text { Complexo da } \\
\text { Mangueira }\end{array}$ & Vidigal & Jacarezinho \\
\hline População & 17860 & 12430 & 37997 \\
\hline Respondentes & 1915 & 965 & 3331 \\
\hline Associação de bairro & 1270 & 940 & 3235 \\
\hline Associação cultural & 410 & 10 & 10 \\
\hline Associação esportiva & 145 & 10 & 38 \\
\hline Associação religiosa & 75 & 0 & 38 \\
\hline Associação filantrópica & 15 & 0 & 0 \\
\hline Associação de pais e mestres & 0 & 5 & 0 \\
\hline Outra & 0 & 0 & 10 \\
\hline
\end{tabular}

FONTE: Science (2000).

NOTA: dados relativos ao ano de 1998 .

Conforme Putnam (1996), mesmo associações com pouca relação direta com a atividade econômica - como instituições esportivas e culturais -, comporiam o capital social, pois reforçariam as relações de cooperação entre os membros da sociedade. A existência desses laços sociais sinaliza a possibilidade de organizar-se ações coletivas que visem à promoção do desenvolvimento social de dada localidade. Logo, a existência da Escola de Samba da Mangueira, que possui um forte apelo cultural na comunidade, pode funcionar como um importante catalisador de redes sociais capazes de promover padrões de sociabilidade e bens coletivos para a comunidade.

Não é tanto a quantidade de associações e sim a qualidade da participação nelas que distingue uma comunidade cívica. Certas estruturas e práticas sociais reforçam as normas e os valores de uma comunidade. Essa idéia de Putnam favorece a compreensão do grau de associativismo da Mangueira, pois, apesar da taxa estimada pela PSECBR ser de apenas $18 \%$ de associados a algum órgão comunitário, a comunidade da Mangueira conta com uma instituição importante, agregadora de sua população, que é sua Escola de Samba. Ela tem tido um papel importantíssimo, como, por exemplo, ao incutir em seus membros hábitos de cooperação, solidariedade e espírito público, contribuindo, assim, para o desenvolvimento comunitário, pois tem o potencial de incorporar e promover a colaboração social.
Assim, além de produzir desfiles de carnaval, a Escola de Samba da Mangueira, desde 1987, tem desenvolvido inúmeros projetos sociais, por meio do Programa Social da Mangueira. São 30 projetos na área de educação (desde infantil até o Ensino Superior), saúde, desportos, lazer, cultura, artes, música dança, formação profissional e assistência jurídica e social. Todos os serviços são totalmente gratuitos para as populações da Mangueira e das comunidades vizinhas.

No início dos anos 1980, aulas de esporte eram dadas na rua abaixo do viaduto próximo à quadra da Escola de Samba; a única condição imposta ao futuro atleta era o dever de freqüentar uma escola de ensino regular.

Em 1987, lideranças da Escola de Samba da Mangueira, preocupadas com o jogo realizar-se embaixo do viaduto, resolveram solicitar ao governo federal o terreno baldio também próximo à Escola de Samba, então pertencente à Rede Ferroviária Federal. O terreno foi cedido por 99 anos, para a execução de projetos sociais coordenados pela Escola de Samba da Mangueira.

Funcionários da empresa multinacional Xerox do Brasil que, além de desfilarem pela Escola de Samba da Mangueira, também contribuíam voluntária e individualmente em ações sociais na comunidade, doando cestas de alimentos e uniformes de futebol para as crianças, conseguiram junto ao Presidente da Xerox do Brasil o apoio financeiro ao projeto esportivo que se elaborava e 
que se denominaria Projeto Vila Olímpica. Assim, samba e solidariedade entrecruzam-se novamente.

Além disso, o governo estadual, apoiando a iniciativa, construiu toda a infra-estrutura do pólo esportivo, com 35 mil metros quadrados. Quanto à participação do poder público na rede, os governos estadual e municipal são os mais atuantes no Programa Social da Mangueira. O governo estadual, por meio da Secretaria Estadual de Educação, administra diretamente o Centro Integrado de Educação Pública (CIEP) Nação Mangueirense; além disso, patrocina o projeto "Artisticamente Mangueira" elaborado pela direção desse colégio. O governo municipal, por meio de convênio, possui uma atuação mais ampla, por meio das Secretarias Municipais de Saúde, Educação, Cultura e Desenvolvimento Social, indo além de mero repassador de verbas, no sentido de responsabilizar-se pelas diretrizes técnicas e pela ampliação do atendimento a toda a comunidade da favela e adjacências.

A empresa que compõe a rede desde a implantação dos projetos e que injeta a maior soma de recursos é a Xerox do Brasil, por meio do Instituto Xerox. Ela investe, aproximadamente, $\mathrm{R} \$$ 1,26 milhão por ano em três grandes projetos.

Desde o ano 2000, a empresa que está em segundo lugar em contribuições, investindo anualmente R \$ 400 mil no Programa Social da Mangueira, é a BR Distribuidora-Petrobrás, por meio do Projeto Centro Cultural BR-Mangueira.

Em relação à integração com a comunidade, o Programa Social da Mangueira possui um setor denominado Atendimento Comunitário, realizado por um morador da favela que lá habita há 40 anos. Seu papel consiste em estabelecer uma relação direta com os moradores, com os presidentes das associações de moradores e com as igrejas da comunidade.

Um indicador expressivo é o número de parcerias que foram agregando-se ao longo dos anos. Em 1988 havia três projetos sociais com apenas duas empresas privadas parceiras. Em 1999, o Programa passou a ter dezesseis projetos sociais com a parceria de 24 empresas privadas; em 2001 passou a contar com 47 parcerias: 27 empresas privadas, três universidades privadas, sete órgão públicos e dez relacionados à organização da sociedade civil, como ONGs, associações, sindicatos, entidades de classe e instituições filantrópicas.

Em quase duas décadas de trabalho social, em apenas 15 desses projetos 25000 atendimentos foram realizados, além de 60000 pessoas serem atendidas pelo Projeto Vidro é Comida, Saúde e Educação, que recolhe vidros em troca de uma cesta de gêneros alimentícios.

O sonho da maioria dos jovens que participam dos projetos de capacitação profissional é o de conseguir um trabalho e serem reconhecidos pelos pais e pela sociedade. Os resultados apontam que $70 \%$ dos adolescentes que participam desses projetos são absorvidos pela empresa em que fizeram estágio.

Em entrevistas, alguns coordenadores dos projetos sociais afirmaram receber frequientemente informações das escolas municipais sobre a melhora significativa do rendimento escolar dos alunos que participam das atividades do Programa Social da Mangueira.

O dinamismo da Escola de Samba da Mangueira em agregar parceiros na construção de uma rede de colaboração na resolução dos problemas sociais da comunidade já lhe renderam três prêmios: dois da rádio $\mathrm{BBC}$ de Londres e um do Programa das Nações Unidas para a Infância e Adolescência (UNICEF), como o melhor projeto social da América Latina e depois como Programa exemplar para o Terceiro Mundo. Recebeu também, como reconhecimento nacional e internacional, a visita de presidentes de República: Fernando Henrique Cardoso (Brasil), Bill Clinton (Estados Unidos) e Nelson Mandela (África do Sul).

A Escola de Samba da Mangueira faz questão de ancorar todos os projetos em sua tradição cultural: verde (esperança) e rosa (amor). Sendo assim, todos os funcionários usam uniformes com o logotipo da Escola e com as cores verde e rosa, além de alguns projetos terem o nome de "Nação Mangueirense": uma das quatro creches, o CIEP (com escolarização da $5^{a}$ série do Ensino Fundamental ao Ensino Médio) e o posto de saúde. Desse modo, a idéia é prevalecer a identidade de ser "mangueirense" ao ocupar o espaço da cidadania. Esse parece um aspecto fundamental dos vínculos associativos vindos da mobilização dos atores envolvidos no Programa Social da Mangueira.

Em suma, constata-se que a parceria entre empresas, poder público e comunidade tem 
facilitado a implementação e o desenvolvimento das ações sociais comunitárias. Os três atores têm atuado na seguinte direção: a Escola de Samba, fornecendo o capital social, e as empresas e o poder público fornecendo o capital financeiro e as diretrizes técnicas.

\section{CONSIDERAÇÕES FINAIS}

Este artigo visou a delinear uma nova forma de gestão de política social, cujo objetivo é anunciar as perspectivas brasileiras atuais do novo papel do Estado, de empresas e da sociedade civil. Tomamos como estudo de caso o Programa Social da Mangueira, que, como vimos, mostra essas tendências ao ser executado por uma rede de parcerias entre os governos federal, estadual e municipal; empresas; universidades; organizações não-governamentais; associações e entidades de classe e a comunidade, na implementação de políticas sociais para uma comunidade de baixa renda - a favela da Mangueira. Em nosso caso, é uma escola de samba a forte condutora e estimuladora dessa rede: a Escola de Samba Estação Primeira de Mangueira.

Como pudemos observar, foi nos anos 1980 que o Programa Social da Mangueira foi elaborado. $\mathrm{O}$ cenário político da época trazia em seu bojo o processo de redemocratização do país e o prenúncio da promulgação da nova Constituição Federal. Novos mecanismos legais e institucionais - como a descentralização administrativa e a participação cidadã - foram canalizados pelo aparelho estatal para o desenvolvimento de políticas sociais em nível local. Foi nessa época que o governo federal cedeu à comunidade um terreno da Rede Ferroviária Federal e o governo do estado ficou responsável pela construção de toda a infraestrutura da Vila Olímpica, juntamente com o apoio do governo municipal.

Não podemos perder de vista a dimensão do Estado nessa rede. Assim, lembramos de Peter Evans, que afirma que a sinergia entre o Estado, o mercado e a sociedade civil fracassa não pela ausência de capital social, mas pela ausência do engajamento político e social estatal. Quando o Estado passa de ator regulador da interação social a indutor e/ou mobilizador de capital social, ligando cidadãos e articulando-se a um conjunto de relações que ultrapassam a divisão público-privado, ele aumenta a sua eficácia governamental e cria um círculo virtuoso de mudança institucional. $\mathrm{Na}$ Mangueira o Estado foi capaz de patrocinar uma iniciativa comunitária, passando de ator regulador a um ativo mobilizador de capital social. Assim, o ativismo institucional do Estado estimulou redes cívicas a ganharem uma vida autônoma, como é o caso do Programa Social da Mangueira, gerenciado em parceria com a Escola de Samba da Mangueira, como representante legítima da comunidade da favela.

Vimos também que o cenário da economia política passou a intermediar o surgimento de novos valores entre alguns setores do empresariado. Uma parte desse empresariado passa a reconhecer os graves problemas sociais no país, assim como que sua empresa pode ter uma importante função social no equilíbrio da sociedade. Portanto, a responsabilidade passa a ser assumida por algumas entidades empresariais. Assim, pudemos vislumbrar algumas iniciativas inovadoras no Brasil, em que diversos atores sociais passaram a cooperar para minimizar a dívida social brasileira. Trata-se de um novo arranjo institucional de cooperação com o poder público e a sociedade civil, instaurado a partir da implementação de práticas de governança.

Como pudemos observar, são a capacidade gerencial sincronizada do Programa Social da Mangueira com seus parceiros, no espírito cívico da Escola de Samba da Mangueira e no orgulho artístico da comunidade os aspectos mais significativos do êxito desse programa social.

Com relação à governança estabelecida entre o poder público, percebemos que passam por um intenso processo de aprendizagem, na medida em que tanto a Escola de Samba da Mangueira como os governos estão elaborando ações compartilhadas e contracenadas em um ambiente desconhecido por ambos. É um processo bastante complexo que implica absorção das novas leis que garantem os direitos das crianças e dos adolescentes, das dinâmicas de comunicação e negociação e do intercâmbio de informações entre o público e o privado, ou seja, é um novo espaço público não-estatal que se constrói e em que a participação e a representação da sociedade civil ainda consolidam-se. Entendemos que relações sinérgicas não são garantidas por meio de lei, convênio ou contrato e sim por meio de um processo construído gradualmente, no sentido de ser capaz de amadurecer as relações de confiança, reciprocidade e do próprio aprendizado gerencial e democrático. 
Talvez os resultados de nosso estudo pareçam otimistas demais - na medida em que constatamos que a governança estabelecida no Programa Social da Mangueira é bem-sucedida -, mas ainda há muito que fazer. Apesar de o Programa Social da Mangueira desenvolver-se ao mesmo tempo a partir de ingredientes cultura cívica da comunidade e do engajamento de fortes instituições, como a Escola de Samba da Mangueira, empresas privadas e o poder público, a sinergia entre esses atores não é um fato dado. É preciso constância de propósitos. Ainda é necessário que tanto o poder público quanto a Escola de Samba da Mangueira envolvam-se efetivamente com a comunidade, tornando-a parceira nesse aprendizado. Destacase a necessidade de uma atuação mais eficaz do poder público em relação ao desenvolvimento econômico e social da comunidade, com projetos de infra-estrutura urbana, geração de renda e educação ambiental contínua para a população. Em caso contrário, a ausência e/ou a descontinuidade dessas políticas geram demandas que acabam recaindo sobre a Escola de Samba da Mangueira, que - na maioria das vezes - não tem condições de responder sozinha a elas, sem o compromisso do poder público.

Finalmente, dado o quadro sinistro de miséria em nossas favelas: falta de oportunidades, de amparo de políticas estatais consolidadas, da existência da rede do tráfico e de tudo que destrói as crianças e jovens pobres do Brasil, acreditamos que o bem-estar pode chegar ao cidadão por meio de ações pontuais de solidariedade da iniciativa privada. Contudo, não será somente a responsabilidade social das empresas que dará conta da dívida social, pois somente o Estado pode garantir que os bens de consumo coletivo alcancem a todos pela simples razão do direito de cidadania. Não como um Estado motor e promotor de domínio exclusivo do bem-estar público, porém sim por meio da sinergia de cooperação entre empresa, sociedade civil e Estado, que pode reforçar a concepção ampla de democracia. Em caso contrário, é difícil sustentarmos políticas dinâmicas e estabelecer vínculos que possam vir a responder às expectativas dos cidadãos de maneira digna $\mathrm{e}$ eficiente.

Maria Alice Nunes Costa (alicecosta.rj@uol.com.br) é cientista política, pesquisadora da Fundação Oswaldo Cruz (FIOCRUZ) e doutoranda em Planejamento Urbano e Regional no Instituto de Pesquisa e Planejamento Urbano da Universidade Federal do Rio de Janeiro (IPPUR-UFRJ).

\section{REFERÊNCIAS BIBLIOGRÁFICAS}

ABU-EL-HAJ, J. 1999. O debate em torno do capital social : uma revisão crítica. $B I B$, Rio de Janeiro, n. 47, p. 65-79, $1^{\circ}$ semestre.

AVRITZER, L. 1995. Cultura política, atores sociais e democratização. Revista Brasileira de Ciências Sociais, São Paulo, ano 10, n. 28, p. 109-122, jun.

. 1997. Um desenho institucional para o novo associativismo. Lua Nova, São Paulo, n. 39 , p. $148-174$.

CARVALHO, J. M. 1995. Desenvolvimiento de la ciudadanía en Brasil. Ciudad de México : Fondo de Cultura Económica.

CASTELLS, M. 1999. A era da informação : economia, sociedade e cultura. V. 2 : O poder da identidade. Rio de Janeiro: Paz e Terra.

CERNEA, M. 1993. Como os sociólogos vêem o desenvolvimento sustentável. Finanças \& Desenvolvimento, Washington, D. C., p. 1113, Dec.

CHEIBUB, Z. B. \& LOCKE, R. M. 2000. Valores ou interesses? Reflexões sobre a responsabilidade social das empresas. In : KIRSCHNER, A. M., GOMES,E.R.\& CAPPELLIN, P. (org.) Empresa, empresários e globalização. Rio de Janeiro : RelumeDumará.

COLEMAN, J. 1988. Social Capital in the Creation of Human Capital. American Journal of Sociology, v. 94, Supplement, p. S95-S120.

1997. Norms of Social Capital.In:RADNITZKY, G. \& BERNHOLZ, P. Economic Imperialism. Paragon : House Publishing.

DINIZ, E. 1995. Governabilidade, democracia e reforma do Estado: os desafios da construção 
de uma nova ordem no Brasil dos anos 1990. Dados, Rio de Janeiro, v. 38, n. 3, p. 385-415. 1997. Crise, reforma do Estado e governabilidade. Rio de Janeiro: Fundação Getúlio Vargas.

EVANS, P. 1996. Government Action, Social Capital and Development : Reviewing the Evidence on Synergy. World Development, v. 24, n. 6, p. 1119-1132.

FERNANDES, R. C. 1995. Elos de uma cidadania planetária. Revista Brasileira de Ciências Sociais, São Paulo, n. 28, p.15-34, jun.

GOMES, E. R. \& GUIMARÃES, F. 2000. Os empresários entre a tradição e a renovação : o caso do PNBE. Revista Internacional de Estudos Políticos, Rio de Janeiro, v. 2, n. 1, abr.

INSTITUTO ETHOS. 2000. Indicadores Ethos de responsabilidade social. Instrumento de avaliação e planejamento para empresas. São Paulo: Instituto Ethos de Empresas e Responsabilidade Social.

KLIKSBERG, B. 1999. Capital social y cultura : claves esenciales del desarrollo. Revista de la CEPAL, Santiago de Chile, v. 69, p. 85-112, dec.

LECHNER, N. 1997. Tres formas de coordinación social. Revista de la CEPAL, Santiago de Chile, v. 61, n. 39, p. 7-17, abr.

MELO NETO, F. P. de \& FROES, C. 1999. Responsabilidade social e cidadania empresarial. Rio de Janeiro : Qualymark.

PEREIRA, L. C. B. \& GRAU, N. C. 1999. Entre o Estado e o mercado : o público não-estatal. In : . (orgs.). O público não-estatal na reforma do Estado. Rio de Janeiro : Fundação Getúlio Vargas.

PORTES, A. \& LANDOLF, P. 1996. The Downside of Social Capital. The American Prospect, n. 26, p. 18-21, May-Jun.
PUTNAM, R. 1996. Comunidade e democracia. A experiência da Itália moderna. Rio de Janeiro: Fundação Getúlio Vargas.

REILLY, C. 1999. Redistribuição de direitos e responsabilidades. Cidadania e capital social. In : PEREIRA, L. C. B. \& GRAU, N. C. (orgs.). O público não-estatal na reforma do Estado. Rio de Janeiro: Fundação Getúlio Vargas.

ROSANVALLON, P. 1998. A nova questão social. Repensando o Estado-providência. Brasília : Instituto Teotônio Vilela.

SANTOS, W. G. 1993. Mitologias institucionais brasileiras: do Leviatã paralítico ao Estado de natureza. Estudos Avançados, São Paulo, v. 7 , n. 17 , p. 101-116, jan.-abr.

SCIENCE. 2000. Pesquisa sócio-econômica das comunidades de baixa renda. Rio de Janeiro: Sociedade Científica de Ciências Estatísticas.

SEN, A. 1999. Desenvolvimento como liberdade. São Paulo: Cia. das Letras.

SERALGEDIN, I. 1993. Praticando o desenvolvimento sustentável. Finanças \& Desenvolvimento, Washington, D. C., p. 6-10, dez.

SKIDMORE, D. 2001. Sociedade civil, capital social e desenvolvimento econômico. In : ABREU, A. A. (org.). Transição em fragmentos: desafios da democracia no final do séc. XX. Rio de Janeiro : Fundação Getúlio Vargas.

TENDLER, J. 1998. Bom governo nos trópicos : uma visão crítica. Brasília : Escola Nacional de Administração Pública.

TINDALE, S. 1994. Sustentando a democracia social: política do meio ambiente. In : MILIBAND, D. (org.).Reinventando a esquerda. São Paulo : UNESP

WORLD BANK. 1992. Governance and Development. Washington, D. C. : The World Bank Group.

\section{OUTRAS FONTES}

IstoÉ. 2000. São Paulo, n.1588, 8.mar., p. 7-9. 